\title{
Impact of childhood and adulthood socioeconomic position on cause specific mortality: the Oslo Mortality Study
}

\author{
B Claussen, G Davey Smith, D Thelle
}

See end of article for authors' affiliations

.....................

Correspondence to: Dr B Claussen, Institute of General Practice and Community Medicine, PO Box 1130 Blindern, $\mathrm{N}-0317$ Oslo, Norway: bjorgulf.claussen@ samfunnsmed.uio.no

Accepted for publication 2 May 2002

\begin{abstract}
Objective: To study the impact of childhood and adulthood social circumstances on cause specific adult mortality.

Design: Census data on housing conditions from 1960 and Personal Register income data for 1990 were linked to 1990-94 death registrations, and relative indices of inequality were computed for housing conditions in 1960 and for household income in 1990.

Participants: The 128723 inhabitants in Oslo aged 31-50 years in 1990.

Main results: Adulthood mortality was strongly associated with both childhood and adulthood social circumstances among both men and women. Cardiovascular disease mortality was more strongly associated with childhood than with adulthood social circumstances, while the opposite was found for psychiatric and accidental/violent mortality. Smoking related cancer mortality was related to both adulthood and childhood social circumstances in men, but considerably more strongly to adult social circumstances.

Conclusions: Childhood social circumstances have an important influence on cardiovascular disease risk in adulthood. Current increases in child poverty that have been seen in Norway over the past two decades could herald unfavourable future trends in adult health.
\end{abstract}

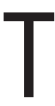
he relation between adverse childhood social circumstances and higher adulthood mortality risk has been demonstrated in several studies, especially with respect to cardiovascular disease. ${ }^{1-7}$ In a 21 year follow up of 5645 men aged 35-64 years from 27 workplaces in the west of Scotland, mortality from coronary heart disease, stroke, lung cancer, stomach cancer, and respiratory disease was higher in those whose fathers had manual jobs compared with those with fathers in professional or managerial occupations. ${ }^{34}$ Adjustment for adult socioeconomic position and risk factors at survey entry had little influence on the relative risks of stroke and stomach cancer mortality associated with less favourable childhood social circumstances, but attenuated the increased risk of coronary heart disease and respiratory disease mortality among those from poorer childhood backgrounds, and essentially eliminated the association of childhood background and accidental/violent death or lung cancer mortality. Conversely, the Finnish Kuopio project found no independent influence of childhood social position on cardiovascular mortality, ${ }^{8}$ but ischaemic ECG patterns elicited by an exercise test were associated with childhood socioeconomic position. ${ }^{5}$

The relative importance of childhood and adulthood social circumstances as predictors of cause specific mortality has clear implications for considerations regarding disease aetiology. Previous studies tend to have been confined to small and selected male populations, however. In this report we have analysed Norwegian routine statistics to investigate the impact of both early life and adulthood socioeconomic circumstances on adult mortality in a large, unselected, population sample of men and women.

\section{METHODS}

All Norwegians were assigned a Personal Identification Number in 1964 that was projected back to the census of 1960 for those living in Norway at the time. Thus it was possible to link census data from 1960, the 1990 Personal Register, and the mortality register 1990-94 in order to study social conditions over a span of 30 years and subsequent mortality.

The data included all 128723 persons aged 31 to 50 years who lived in the municipality of Oslo on 1 January 1990. This sample was chosen because they were children and teenagers in 1960, and thus the 1960 census data provided information on childhood social circumstances. Some 1655 deaths occurred in the 1990-1994 period.

\section{Mortality}

All death certificates are registered with Statistics Norway. Causes of death were classified as cardiovascular diseases (ICD-9 390-459), cancer (140-208), psychiatric (290-319), accidents/violence (800-999) and others. Cancers were also divided into smoking related, (lip (140), tongue (141), mouth and pharynx (143-149), oesophagus (150), pancreas (157), respiratory tract (160-163), and urinary tract (188-189)), and non-smoking related (other cancers).

\section{Housing conditions}

The 1960 census recorded details on six aspects of housing (table 1), which are known to be related to the living standards of the households in Oslo. ${ }^{9}$ These variables were summarised according to the values in table 1 into a Housing Index, ranging from 0 (least favourable) to 8 (most favourable). Given small numbers in the least favourable two groups ( 0 and 1$)$ and the most favourable two groups ( 7 and 8 ) these were collapsed, giving an index from 1 to 7 (table 2).

\section{Income}

A census was not held in 1990, but was replaced by a Personal Register in Statistics Norway, which does not contain housing information. Instead we used taxable earnings from the taxation authorities. These were yearly wages, social security benefits, and other earnings minus a personal allowance of about $25000 \mathrm{NKr}$ and other tax deductible expenditures. The taxable incomes were added for married couples and taxes 
Table 1 Mortality rates 1990-94 by housing conditions in 1960 among 31-50 years old inhabitants in Oslo 1.1.90

\begin{tabular}{|c|c|c|c|c|c|c|}
\hline \multirow{2}{*}{$\begin{array}{l}\text { Housing conditions } \\
1960 \text { (values in the } \\
\text { Housing index) }\end{array}$} & \multicolumn{3}{|l|}{ Men } & \multicolumn{3}{|l|}{ Women } \\
\hline & Number & $\begin{array}{l}\text { Mortality* } \\
\text { 1990-94 }\end{array}$ & $\mathrm{p}$ Value & Number & $\begin{array}{l}\text { Mortality* } \\
\text { 1990-94 }\end{array}$ & $\mathrm{p}$ Value \\
\hline \multicolumn{7}{|l|}{ Type of dwelling } \\
\hline (0) Block & 20153 & 39 & & 19453 & 21 & \\
\hline (1) Row house & 15023 & 30 & & 14932 & 17 & \\
\hline (2) Detached house & 15297 & 28 & 0.009 & 16629 & 16 & 0.042 \\
\hline \multicolumn{7}{|c|}{ Rooms per household capita } \\
\hline$(0) \leqslant 0.5$ & 11386 & 43 & & 11387 & 20 & \\
\hline (1) $0.51-1$ & 32147 & 32 & & 32159 & 16 & \\
\hline$(2)>1$ & 6940 & 22 & $<0.001$ & 7468 & 19 & 0.680 \\
\hline \multicolumn{7}{|l|}{ Ownership to dwelling } \\
\hline (0) No & 31767 & 36 & & 31194 & 18 & \\
\hline (1) Yes & 18706 & 28 & $<0.001$ & 19820 & 16 & 0.018 \\
\hline \multicolumn{7}{|l|}{ Telephone in dwelling } \\
\hline (0) No & 26425 & 41 & & 26170 & 19 & \\
\hline (1) Yes & 24048 & 27 & $<0.001$ & 24844 & 15 & $<0.001$ \\
\hline \multicolumn{7}{|l|}{ Toilet in dwelling } \\
\hline (0) No & 16675 & 40 & & 17986 & 19 & \\
\hline (1) Yes & 33798 & 30 & $<0.001$ & 33028 & 16 & 0.022 \\
\hline \multicolumn{7}{|l|}{ Bath in dwelling } \\
\hline (0) No & 15348 & 42 & & 16167 & 20 & \\
\hline (1) Yes & 35125 & 30 & $<0.001$ & 34847 & 15 & $<0.001$ \\
\hline Sum & 50473 & 34 & & 51014 & 18 & \\
\hline
\end{tabular}

*Age adjusted mortality per 10000 person years. †p Values for trend or homogeneity.

were subtracted, giving net household income. This amount was divided by the figure of "consumer units" in the household, which is 1.0 for the first adult person, 0.7 for spouse and each child of 16 or older living at home without taxable income, and 0.5 for each child under 16 years of age. If older children had taxable earnings, they were registered as a one person household.

To compare the middle aged standard of living with the childhood/adolescence standard of housing conditions, net household income per consumer unit was grouped in seven categories, with similar proportions of the population falling into the categories as is seen with the Housing Index: (1) 1-25000 NKr, (2) $25001-50000 \mathrm{NKr}$, (3) $50001-75000 \mathrm{NKr}$, (4) $75001-100000 \mathrm{NKr}$, (5) $100001-125000 \mathrm{NKr}$, (6) $125001-150000 \mathrm{NKr},(7) 150001+$ NKr. (\$1 was about 6.25 $\mathrm{NKr}$ in 1990).

\section{Missing data}

Completing the census is a legal obligation. Those who did not return the form by post were visited at home by officials who collected the data. Although there were no missing forms some people did not answer all questions on the forms. Some $18 \%$ of the sample did not have data for any or all the housing questions in 1960. The 1990 Tax Register recorded zero or negative income for $6 \%$ of the sample, which were regarded as missing values. Responders were those both answering the 1960 housing issues and having an income in 1990 above zero. A total of $21 \%$ had incomplete data. The most common reason was not living in Norway in 1960. Some 11\% were born outside Norway and $2 \%$ were Norwegians living abroad in 1960, both groups therefore not participating in the 1960 census. Sixty one per cent of missing cases were attributable to these reasons. The relative rates of mortality for those excluded from full analysis compared with those included were 1.05 (95\% CI 0.92 to 1.20 ) for men and 1.04 (0.84 to 1.30$)$ for women, indicating small differences in mortality risk.

\section{Statistics}

Crude mortality rates by housing variables and income were directly age standardised with four five-year age bands in the statistical package Stata, with the whole cohort as standard population (tables $1-3$ ).

Table 2 Mortality rates 1990-94 by indices of housing conditions in 1960 and net household income per consumer unit in 1990

\begin{tabular}{|c|c|c|c|c|c|c|c|c|}
\hline \multirow[b]{3}{*}{$\begin{array}{l}\text { Index } \\
\text { values }\end{array}$} & \multicolumn{4}{|l|}{ Men } & \multicolumn{4}{|l|}{ Women } \\
\hline & \multicolumn{2}{|l|}{1960} & \multicolumn{2}{|l|}{1990} & \multicolumn{2}{|l|}{1960} & \multicolumn{2}{|l|}{1990} \\
\hline & Number & $\begin{array}{l}\text { Mortality* } \\
\text { 1990-94 }\end{array}$ & Number & $\begin{array}{l}\text { Mortality* } \\
1990-94\end{array}$ & Number & $\begin{array}{l}\text { Mortality* } \\
\text { 1990-94 }\end{array}$ & Number & $\begin{array}{l}\text { Mortality* } \\
\text { 1990-94 }\end{array}$ \\
\hline 1 (poor) & 4502 & 48 & 1980 & 59 & 4566 & 27 & 2285 & 32 \\
\hline 2 & 5240 & 49 & 5200 & 55 & 5285 & 20 & 6252 & 25 \\
\hline 3 & 10324 & 38 & 11061 & 37 & 9855 & 18 & 12444 & 20 \\
\hline 4 & 11685 & 30 & 13338 & 26 & 11625 & 15 & 14287 & 16 \\
\hline 5 & 7705 & 29 & 10608 & 27 & 8118 & 13 & 10088 & 15 \\
\hline 6 & 5353 & 26 & 5031 & 23 & 5428 & 19 & 3746 & 13 \\
\hline 7 (well off) & 5664 & $20 \dagger$ & 3255 & $18 \dagger$ & 6137 & $17 \dagger$ & 1912 & $9 \dagger$ \\
\hline Sum & 50473 & 34 & 50473 & 34 & 51014 & 18 & 51014 & 18 \\
\hline
\end{tabular}

*Age adjusted mortality per 10000 person years. $† p$ Values for test for trend across housing conditions index categories $<0.001$. 


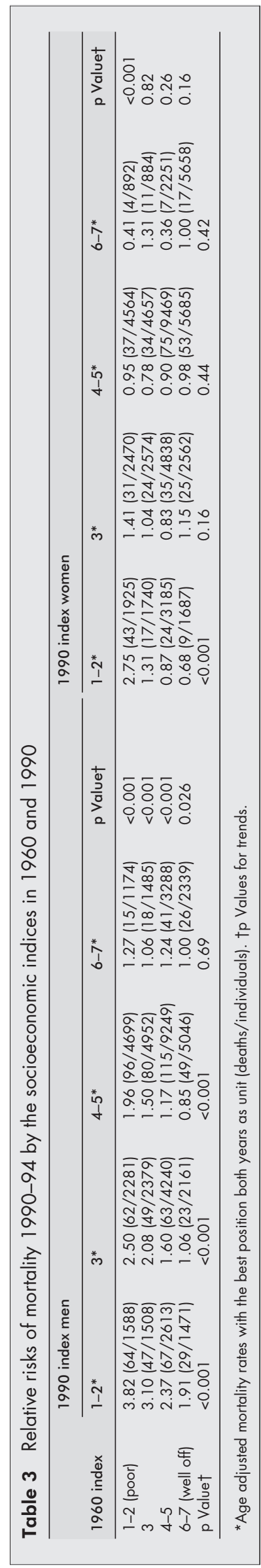

To compare mortality rates by the seven social positions, a measure called the relative index of inequality (RII) was used..$^{11}{ }^{11}$ The measures of socioeconomic position in 1960 and 1990 have different (although similar) proportions of the population in each of the seven groups. Therefore a direct comparison of rate ratios is not possible. The RII is constructed to avoid this problem.

For the 1960 and 1990 socioeconomic position measures, each group was assigned a value between 0 and $\mathrm{l}$ according to the proportion of participants with a higher socioeconomic position than the midpoint of each group within the hierarchy which that person lay, starting with the best off group (group 7). In the case of the 1960 housing index a proportion of 0.12 of all men in 1960 were in the highest Housing Index group, the midpoint person would have a proportion of 0.06 of the population having more favourable socioeconomic circumstances, giving a socioeconomic position (SEP) score of 0.06 for this group. In the next most favourable group (group 6), there were $11 \%$ of the population. All $12 \%$ in the better housing conditions group (group 7) were taken to be in more favourable circumstances than this group, and for the midpoint person a proportion of 0.055 of the population in group 6 would be above them $(0.11 / 2)$. The SEP score for this group was therefore 0.12 plus $0.055=0.175$. This procedure was then continued for the rest of the groups, and the method applied both to 1960 housing index scores and the 1990 income groups. The SEP scores were related to mortality in logistic regressions:

$\log (D)=a+b S E P+c A g e c a t+e$

where D is the odds of death, and Agecat is the five year age bands, providing age adjustment for the RII. Exponentiating $b$ yields the RII, which is the odds ratio of mortality for the hypothetically poorest individual compared with the hypothetically richest individual; SEP score $=1$ compared with SEP score $=0$. The larger the RII, the greater is the degree of inequality of deaths across the socioeconomic hierarchy.

\section{RESULTS}

Age adjusted mortality when the cohort was from 31 to 55 years of age in 1990-94, was 34 per 10000 person years for men and 18 for women (table 1). Male mortality was lower among those with better housing conditions in 1960 . Mortality was particularly related to not having a telephone, bath or toilet inside the dwelling, but also to crowding and type of dwelling for men. Female mortality followed the same pattern, but the differences tended to be smaller.

\section{Indices of socioeconomic position}

A Housing Index with seven steps was constructed using the values in table 1 . The age adjusted mortality rate for men was 2.4 times higher in the group in least favourable housing circumstances than the group in the most favourable circumstances during childhood (table 2). The corresponding figure for women was 1.6.

Mean net household income per consumer unit in 1990 was $81203 \mathrm{NKr}$ ( 1990 \$12 992) for men and $78799 \mathrm{NKr}$ (\$12 608) for women. The age adjusted mortality rate for men was 3.3 times higher in the lowest income group compared with the highest; among women the equivalent difference was 3.6 (table 2).

The correlation between the two indices was low, at 0.08 for both men and women. In table 3 mortality rates across a compressed form of the indices of social position in 1960 and 1990 are presented. For men in general, the 1960 index predicted mortality within strata of the 1990 index and vice versa. For women the patterns were less clear, perhaps because of the low number of deaths in some strata. 
Table 4 Relative indices of inequality (RII) in 1960 and 1990 for cause specific mortality 1990-94

\begin{tabular}{|c|c|c|c|c|c|c|}
\hline \multirow[b]{2}{*}{ Causes of death } & \multicolumn{3}{|c|}{ Men $(n=50473)$} & \multicolumn{3}{|c|}{ Women $(n=51014)$} \\
\hline & $\begin{array}{l}\text { Number of } \\
\text { deaths }\end{array}$ & 1960 RII* & 1990 RII* & $\begin{array}{l}\text { Number of } \\
\text { deaths }\end{array}$ & 1960 RII* & 1990 RII* \\
\hline Cardiovascular & 201 & $2.79(1.71$ to 4.55$)$ & 2.21 (1.33 to 3.68$)$ & 54 & $3.96(1.52$ to 10.3$)$ & 2.63 (0.98 to 7.04$)$ \\
\hline Cancer, smoking related & 55 & $4.47(1.72$ to 11.7$)$ & 11.5 (4.10 to 32.3$)$ & 33 & $1.47(0.45$ to 4.75$)$ & 1.45 (0.85 to 2.48$)$ \\
\hline Cancer, not smoking related & 117 & $1.03(0.55$ to 1.93$)$ & $1.40(0.72$ to 2.72$)$ & 186 & $1.00(0.61$ to 1.64$)$ & 0.58 (0.16 to 2.16$)$ \\
\hline Psychiatric & 142 & 12.2 (5.37 to 28.0$)$ & 16.9 (3.35 to 39.1$)$ & 24 & $5.75(2.34$ to 14.1$)$ & 15.0 (2.08 to 109$)$ \\
\hline Accidents/violence & 181 & 1.74 (1.04 to 2.92$)$ & $4.21 \quad(2.44$ to 7.24$)$ & 87 & $1.07(0.51$ to 2.22$)$ & 5.02 (2.25 to 11.2 ) \\
\hline Others & 148 & 2.74 (1.66 to 4.55$)$ & 1.77 (1.06 to 2.96$)$ & 62 & 2.87 (1.23 to 6.67$)$ & 5.75 (2.34 to 14.1$)$ \\
\hline All deaths & 844 & $2.63(2.06$ to 3.35$)$ & 3.14 (2.44 to 4.04$)$ & 446 & 1.55 (1.12 to 3.13$)$ & 2.50 (1.77 to 3.53$)$ \\
\hline
\end{tabular}

${ }^{*}$ Age adjusted relative indices of inequality $(95 \%$ confidence intervals)

\section{Relative indices of inequality for mortality}

Table 4 shows cause specific and all cause death rates by childhood/adolescence (1960) and adulthood (1990) socioeconomic position. Socioeconomic differences were seen for most of the mortality categories that have been examined; the main exceptions being cancers not related to smoking (for which sizeable gradients were seen for neither men nor women), and cancers related to smoking (for which sizeable effects were not seen for women, although they were seen for men). Psychiatric mortality was almost exclusively made up of deaths attributed to alcohol or drug dependence.

Cardiovascular mortality was more strongly related to childhood socioeconomic circumstances than to adulthood circumstances for both men and women (table 4). Other causes of death tended to be more strongly associated with income in adulthood than housing conditions in childhood.

In table 5, the 1960 and 1990 socioeconomic position indicators are related to all cause and cause specific mortality after mutual adjustment. In line with the simple associations, childhood social circumstances seem particularly important with respect to cardiovascular disease mortality in both men and women, and mortality within the "other causes" group for men. Interaction terms indicated that mortality for people in adverse social circumstances both in 1960 and 1990 were above the levels predicted by a simple multiplicative model for all cause and cardiovascular mortality among men and women, accidental and violent deaths among men, and psychiatric mortality among women.

\section{DISCUSSION}

This study confirms the finding that socioeconomic deprivation in early life is associated with adulthood mortality. ${ }^{1-4}$ The greater relative importance of childhood social circumstances than adulthood social circumstances for cardiovascular disease mortality, reported previously for men, ${ }^{4}$ was also seen in this study. We have extended previous findings to show that the same pattern is seen for women. For other cause of death groups, adulthood social position tended to be of greater relative importance. This study is based on an entire population sample and thus has advantages over most previous investigations of this issue.

We found strong associations of both childhood and adulthood social circumstances and all cause mortality in this study, in line with previous investigations. ${ }^{32}$ A striking inverse association between adulthood income and mortality was seen in the present data, as in previous studies from other countries, ${ }^{13} 14$ and previous studies from Norway. ${ }^{15}{ }^{16}$ While it is sometimes suggested that ill health in adulthood leads to lower income, and thus generates the association between income and mortality, it is clear that adulthood health cannot influence childhood social circumstances. Thus the observation of a marked gradient between childhood socioeconomic position and all cause mortality is a clear demonstration that

\section{Key points}

- The association between mortality and childhood as well as adulthood social position seems to be robust.

- A clear cumulative influence of social circumstances across the lifecourse in mortality risk is demonstrated.

- Childhood social position have an important influence on cardiovascular disease risk in adulthood also for women.

- Smoking related cancers, accidents/violence and psychitric causes of death for both sexes were more related to adulthood social position than to childhood position.

- Increasing child poverty in Norway could herald unfavourable future trends in adult health.

socioeconomic differentials in mortality are not primarily caused by such reverse causation, adding to previous evidence in this regard..$^{17} 18$

Income data were not available for households in 1960, therefore housing condition information has been used. In Norway, housing conditions have been shown to correlate strongly with other measures of socioeconomic position. ${ }^{9}$ Norwegian families spend much of their income on their dwelling, making this a particularly sensitive indicator of social circumstances.

The highest risk of mortality among men and women was observed in the group who were poor both in childhood and in adulthood, but clear gradients were found through the steps of the 1960 and 1990 social position measures. This demonstrates a clear cumulative influence of social circumstances across the lifecourse on mortality risk. ${ }^{419-21}$ In this study, there were significant interactions such that people in adverse socioeconomic circumstances in both childhood and adulthood had higher mortality than would be expected on the basis of a simple multiplicative model. This lifecourse cumulative influence seems especially important for the multifactorial course of cardiovascular disease risk, but also for female psychiatric deaths and male violent deaths suggesting an additional health burden for people who experience economic hardship right the way across their lives.

Clear childhood socioeconomic position effects have also been seen for coronary heart disease in previous studies. ${ }^{6} 72224$ The accumulation of the influences of socially patterned risk factors for cardiovascular disease acting across the lifecourse-from low birth weight, ${ }^{25}{ }^{26}$ suboptimal growth in childhood, ${ }^{27}$ smoking, excessive (binge) alcohol consumption $^{28}$ and high saturated fat/low fruit and vegetable diet in adulthood, and job insecurity in adulthood ${ }^{29}$ would lead the observed pattern-with a contribution of both childhood and adulthood social position to cardiovascular mortality to be anticipated. In previous studies particularly strong influences of childhood social circumstances have been demonstrated for stroke in comparison with coronary heart disease. ${ }^{30} 31$ In this study, however, there were only 39 stroke deaths, reflecting the comparatively young age at death in this cohort. 


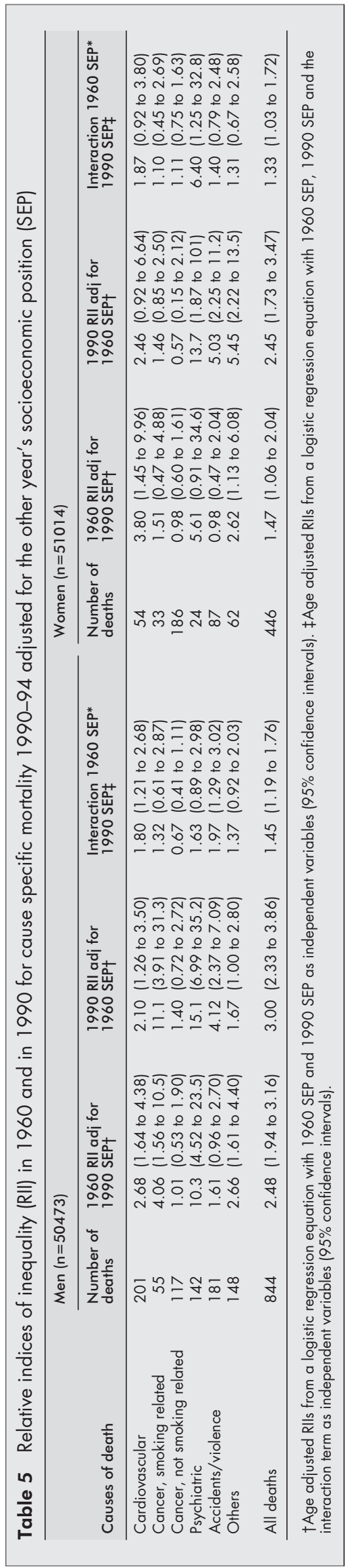

Health related behaviours, such as smoking and binge drinking, tend to be more strongly socially patterned by adulthood rather than childhood social circumstances, ${ }^{32}$ although some influence of childhood social position can be seen, ${ }^{33}$ especially with respect to smoking in women. ${ }^{34}$ This greater influence of adulthood social environment on the maintenance of health related behaviours would lead to the expectation that smoking related and alcohol related causes of death, such as smoking related cancer, psychiatric causes, and accidents/violence, would be more strongly related to adulthood social position, as was observed in our data. This is in keeping with evidence that the influence of childhood social circumstances on adulthood smoking is considerably greater in women than in men. ${ }^{27}$

In this study, we are largely interpreting the associations with housing conditions in early life and income in later life as reflecting socioeconomic circumstances in general. It is also possible that they could be closer correlates of direct causal factors related to disease risk. For example, deprivation in childhood is related to stomach cancer risk. ${ }^{35}$ This is probably attributable to acquisition of Helicobacter pylori infection in childhood, which would be directly related to overcrowded living conditions and ability to maintain adequate hygiene practices (reflected in possession of a toilet within the dwelling or a bath). In this study we do not have enough events to study stomach cancer mortality, but it is also possible that cardiovascular disease risk is influenced by infections acquired in childhood. The dual nature of measures of social positionboth as proxies of underlying general social circumstances, and also as factors that may have a more direct influence on disease risk is a general-but, underdiscussed, aspect of research into socioeconomic inequalities in health.

There are three principal conclusions from our study. Firstly, consideration of the social distribution of adult mortality risk must evaluate the influence of socioeconomic circumstances acting across the entire lifecourse. If data covering only one point in time are used-whether this is early life or adulthood-there are serious limitations to the ability to determine the key socioeconomic influences on health, or to appreciate the magnitude of these influences. Secondly, the influence of socioeconomic circumstances at different stages in life varies between particular causes of death. Cardiovascular disease mortality is particularly influenced by childhood social circumstances, whereas mortality related to adulthood health related behaviours is more strongly influenced by adulthood social position. The specificity of these associations reinforces the limited degree of explanation that can be provided by models of health inequalities based on a notion of a heightened general susceptibility to diseases among those in poor social circumstances. ${ }^{35}$ Finally, current changes in mortality rates for cardiovascular disease reflect in part social changes that occurred some decades ago. Current increases in child poverty that have been seen in many countriesincluding Norway-over the past two decades ${ }^{37}$ could herald unfavourable future trends in adult health.

\section{ACKNOWLEDGEMENTS}

We thank Executive Officer Britt Elin Bråten and Project Leader Finn Gjertsen, Statistics Norway, for linking data, Professor Håkon K. Gjessing, University of Oslo, for statistical advice, and the European Science Foundation's programme "Social Variations in Health Expectancy in Europe" for support.

Authors' affiliations

B Claussen, Institute of General Practice and Community Medicine, University of Oslo, Norway

G Davey Smith, Department of Social Medicine, University of Bristol, UK D Thelle, Centralkliniken, Sahlgrenska Universitetssjukhuset, Gothenburg, Sweden

Funding: our institutions.

Conflicts of interest: none. 


\section{REFERENCES}

1 Forsdahl A. Living conditions in childhood and subsequent development of risk factors for arteriosclerotic heart disease. J Epidemiol Community Health 1978;32:34-7.

2 Barker DJP, Osmond C. Infant mortality, childhood nutrition, and ischaemic heart disease in England and Wales. Lancet 1986;i:1077-81.

3 Davey Smith G, Hart C, Blane D, et al. Adverse socioeconomic conditions in childhood and cause specific adult mortality: prospective observational study. BN 1998;316:1631-5.

4 Davey Smith G, Hart C, Blane D, et al. Lifetime socioeconomic position and mortality: prospective observational study. BM 1997;314:547-52

5 Kaplan GA, Salonen JT. Socioeconomic conditions in childhood and ischaemic heart disease during middle age. BMU 1990;301:1121-3.

6 Wannamethee SG, Whincup PH, Shaper G, et al. Influence of fathers' social class on cardiovascular disease in middle-aged men. Lancet 1996;348: 1259-63.

7 Vagero D, Leon D. Effect of social class in childhood and adulthood on adult mortality Lancet 1994:343:1224-5.

8 Lynch JW, Kaplan GA, Cohen RD, et al. Childhood and adult socioeconomic status as predictors of mortality in Finland. Lancet 1994;343:524-7.

9 Wessel T. Housing and welfare in Norway: compensation or double deprivation? Norsk Geogr Tidsskr 1998;52:209-19.

10 Kunst AE, Mackenbach JP. The size of mortality differences associated with educational level in nine industrialized countries. Am J Public Health 1994;84:932-7.

11 Davey Smith G, Hart C, Hole D, et al. Education and occupational social class: which is the more important indicator of mortality risk? J Epidemiol Community Health 1998;52:153-60.

12 Shaw M, Dorling D, Gordon D, et al. The widening gap: health inequalities and policy in Britain. Bristol: Policy Press, 1999.

13 Kitagawa EM, Hauser PM. Differential mortality in the United States. Cambridge, MA: Harvard University Press, 1973.

14 Sorlie PD, Backlund E, Kehler J. Mortality by economic, demographic, and social characteristics: the national longitudinal mortality study. Am J Public Health 1995;85:949-56.

15 Holme I, Helgeland A, Hjermann I, et al. Four-year mortality by some socioeconomic indicators: the Oslo study. J Epidemiol Community Health 1980;34:48-52.

16 Dahl E. Social inequalities in ill-health: the significance of occupational status, education and income. Results form a Norwegan survey. Sociology of Health and Illness 1994;16:644-67.

17 Blane D, Davey Smith G, Bartley M. Social selection: what does it contribute to social class differences in health? Sociology of Health and Illness 1993;15:1-15

18 Davey Smith G, Bartley M, Blane D. Explanations for socio-economic differentials in mortality: evidence from Britain and elsewhere. Eur $J$ Public Health 1994;4:131-44.

19 Wolfson M, Rowe G, Gentleman JF, et al. Career earnings and death: a longitudinal analysis of older canadian men. J Gerontol 1993;48:5167-79

20 Salhi M, Caselli G, Duchêne J, et al. Assessing mortality differentials using life histories: a method and applications. In: Lopez A, Caselli G,
Valkonen T, eds. Adult mortality in developed countries: from description to explanation. Oxford: Clarendon Press, 1995

21 Mare RD. Socioeconomic careers and differential mortality among older men in the United Stages. In Vallin J, D'Douza S, Palloni A, eds. Measurement and analysis of mortality: new approaches. Oxford: Clarendon Press, 1990

22 Burr ML, Sweetnam PM. Family size and paternal unemployment in relation to myocardial infarction. J Epidemiol Community Health 1980;34:93-5.

23 Reference withdrawn.

24 Notkola V, Punsar S, Karvonen M, et al. Socioeconomic conditions in childhood and mortality and morbidity caused by coronary heart disease in adulthood in rural Finland. Soc Sci Med 1985;21:517-23.

25 Barker DJP. Mothers, babies and health in later life. Edinburgh Churchill Livingston, 1998.

26 Frankel S, Elwood P, Sweetnam P, et al. Birthweight, body-mass index in middle age, and incident coronary heart disease. Lancet 1996;348: 1478-80.

27 Gunnell DJ, Davey Smith G, Frankel S, et al. Childhood leg length and adult mortality: follow up of the Carnegie (Boyd Orr) Survey of Diet and Health in Pre-war Britain. J Epidemiol Community Health 1998; 52: 142-52

28 Hart CL, Davey Smith G, Hole DJ, et al. Alcohol consumption and mortality from all causes, coronary heart disease, and stroke: results from a prospective cohort study of Scottish men with 21 years of follow up. BM 1999;318:1725-9

29 Ferrie JE, Shipley M, Marmot MG, et al. An uncertain future: the health effects of threats to employment security in white-collar men and women. Am J Public Health 1998;88:1030-6.

30 Davey Smith G, Ben-Shlomo Y. Geographical and social class differentials in stroke mortality-the influence of early-life factors. $J$ Epidemiol Community Health 1997;51:134-7.

31 Leon D, Davey Smith G. Infant mortality, stomach cancer, stroke, and coronary heart disease: ecological analysis. BMV 2000;320:1705-6.

32 Blane D, Hart CL, Davey Smith G, et al. Association of cardiovascular disease risk factors with socioeconomic position during childhood and during adulthood. BM 1996;313:1434-8.

33 Lynch JW, Kaplan GA, Salonen JT. Why do poor people behave poorly? Variations in adult health behaviour and psychosocial characteristics, by stage of the socioeconomic lifecourse. Soc Sci Med 1997;44:809-20.

34 Brunner E, Shipley $M$, Blane D, et al. When does cardiovascular risk start? Past and present socioeconomic circumstances and risk factors in adulthood. J Epidemiol Community Health 1999;53:757-64.

35 Davey Smith G, Gunnell D, Ben-Shlomo Y. Life-course approaches to socio-economic differentials in cause-specific adult mortality. In: Leon D Walt G. Poverty, inequality and health. Oxford: Oxford University Press, 2000.

36 Najman JM, Davey Smith G. The embodiment of class-related and health inequalities: Australian policies. Aust N Z J Public Health 2000;24:3-4.

37 Lynch JW, Kaplan GW. Understanding how inequality in the distribution of income affects health. Journal of Health Psychology 1997;2:297-314. 